\title{
Partial Relationships and Epistemic Injustice
}

\author{
J. Y. Lee ${ }^{1}$ (D) \\ Accepted: 16 July 2021 \\ (C) The Author(s), under exclusive licence to Springer Nature B.V. 2022
}

\section{Introduction}

Partiality in philosophy generally refers to a special kind of concern for the interests of certain people over others (Stroud, 2010, p. 134), which can involve "preference or fondness or affection for a particular person." (Scheffler, 2010, p. 99) This version of partiality - that which might apply to our friends, intimates, and family members - can be distinguished from something like egoism, which is "an extreme form of partiality...that...gives overriding importance to just one individual's welfare." (Hooker, 2013, 710) It can also be distinguished from something like preferential commitments to one's own nation-state, which might typically ground debates regarding our local versus global moral responsibilities. (Tronto, 2012, p. 310) And the moral status of our partial relationships can vary accordingly: for instance, we might have the intuition that special moral attention to family members are generally acceptable, but that the same could not be said in regards to a racist group with whom one is associated, given the "pervasive injustice" that characterizes the latter. (Miller, 2005, p. 66) Still, the idea that certain partial ties - in particular, like those involving loving and caring familial relations - can be specially morally valued holds significant sway in ethical literature. Special partial relationships of this kind, it is said, may transform what is required of you morally: in the case of parents and children, for example, perhaps you have duties to provide for your own children, but not for all children. (Keller, 2013, p. 2)

Yet, as Harry Brighouse and Adam Swift point out, even the partial relationships that are taken to be generally permissible sometimes enable participants to "exclude others from the mutual benefits their association yields...in ways that may interrupt equality." (Brighouse and Swift, 2009, p. 44) That we all conduct these partial relationships to varying degrees appears undeniable - it is plausible to say, for instance, that most parents invest greater resources into their own children than other children. (Douglas, 2015, p. 2736) In practice, we might "[assign] more importance to the welfare or will of some individuals or groups than to the welfare or will of others." (Hooker, 2013, p. 717) But the potential for partial relationships to inflict at

\section{J. Y. Lee}

ji.young.lee@sund.ku.dk

1 University of Copenhagen, Øster farimagsgade 5, Copenhagen K, Denmark 
least some degree of moral wrong, or be in tension with values like equality, is also plausible.

Thus, the notion of partiality in the moral realm has long worried philosophers, especially when contrasted with the notion of impartiality. On the one hand, if it is true that "morality...makes us all third parties to our own interests" (Feltham, 2010, p. 2) then it seems that my own interests, preferences, and projects, as well as that of those I love, cannot take special precedence in considerations of what ought to be done morally - I must instead take an impartialist perspective. On the other hand, if we take ourselves to have reason "for patterns of action and emotion towards our parents, siblings, friends, spouses, children..." (Kolodny, 2010, p. 169) then it appears that our close relationships normatively pull us back in the direction of a partial rather than impartial perspective (Wolf, 1992, p. 243).

Varying degrees of such partial associations hold between people - perhaps certain family relationships like parent-child relationships characterize some of the stronger associations, whereas fleeting friendships and cordial acquaintances constitute weaker partial associations. While I will not attempt to resolve this debate here, my view on the matter echoes that of Marilyn Friedman's perspective. Friedman states that personal relationships can "vary widely in their moral value" (Friedman, 1991, p. 820) because they may after all turn out to be exploitative, abusive, or oppressive - in the worst cases. The point to take away from the paragraphs above is simply that partial relationships of the kind described are taken to have palpable effects on ethically significant concepts, such as equality and justice. As such, these relationships are an important site of analysis for juxtaposition with moral concepts.

But I wish to now set aside the question of the purely ethical effects of partial relationships, and explore instead the epistemic dimensions of partial relationships, which generate interesting philosophical questions in their own right. Some have already gestured toward this connection from within ethics: for example, we might acknowledge that knowing certain others' interests particularly well gives us moral reason to maintain and cultivate such relationships. (Crisp, 2018, p. 1) In the social epistemology literature, scholars like Anthony Quinton have pointed out that we "do not subject what our parents tell us in early life to critical examination," (Quinton, 2004 , p. 7) despite also depending on them to develop the very epistemic capacities required to critically discern their claims. Clearly, there are lines of inquiry that lie at the intersection between ethics and social epistemology which might be fruitfully cashed out, providing a dialogical bridge between these fields.

One such contribution that can be made on the topic of partial relationships at the intersection between ethics and social epistemology consists of a critical examination on whether such relationships act as vehicles for epistemic injustice in unique ways. While our survey above shows that partial relationships implicate questions to do with justice and injustice, I am motivated to explore how epistemic injustice, rather than injustice in general, might be specially amplified by partial, rather than impartial, relationships. This analysis would especially benefit the social epistemology literature by providing a context-sensitive account of the transmission of epistemic injustice between agents. In the first part of this paper, I lay out how partial relationships and their typical features are relevantly connected to the potential for, or incidences of, epistemic injustice. I will also show how the standard story told 
about the mechanisms of epistemic injustice fail to satisfyingly explain how partial relationships exacerbate epistemic injustice, thus justifying a need for a deeper analysis of partial relationships in the social epistemology literature. The second part of my paper will proceed to then detail further why partial relationships are a particularly pernicious site of epistemic injustice. I will defend the view that features typical of partial relationships make epistemic injustice easier to mask, harder to identify, and more difficult to correct.

\section{Partial relationships and their epistemic effects}

Sullivan et al. point out that social epistemologists have tended to consider social epistemic exchange at rather abstract dyadic levels (e.g. between a speaker and hearer), as taking place within scientific communities (e.g. as when one might propound the view that things like 'truth' and 'facts' are a matter of "social negotiation or politics" (Goldman, 2009, p. 2)), or perhaps "simulated networks with unclear ecological validity." (Sullivan et al., 2020) Aside from this issue of how we ought to imagine the structure of epistemic social groups and their interaction in relation to knowledge production as a whole, however, the more particularized cares of agents in an epistemic group, and the specific nature of members' relationships with each other, are underanalysed in the social epistemology literature. My objective herein is to highlight the ways we can be epistemically influenced by, and preferential to, our network of partial ties, and to consider how such phenomena is connected to epistemic injustice.

Let us outline the epistemic features we can plausibly take to be typical of partial relationships. We might, for instance, prioritize our lovers' testimonies over that of other, competing testimonies; we may take our friends' advice as more authoritative; and family insights over our affairs may be treated as the most accurate. Epistemically speaking, we might say this phenomenon has ambivalent outcomes: one the one hand, one may argue that allowing our beliefs to be influenced and shaped by our personal relationships constitute "the paradigmatic case of epistemic irrationality," (Paul and Morton, 2018, p. 1) insofar as it is the case that such influence obscures whether the beliefs we hold to be true are actually true. Perhaps, one might say, we have stronger ethical rather than epistemic reasons to epistemically favour our close ties - to provide optimism and moral support for our loved ones, for instance. At the same time, we might say epistemic partiality can be innocuous enough, and even have good consequences. It may just as well be that people who deeply care about one another can influence each other in ways that conduce to better exercise of certain epistemic virtues. For instance, we might be more openminded and non-judgmental of our friends, and we might hold one another to higher epistemic account when it comes to our beliefs and our belief-formation processes, precisely because it matters more to us to do so with our partial ties.

Despite this ambivalence - or perhaps even because of this ambivalence - there is a scenario where epistemic influence conducted through partial relationships might plausibly devolve into something more sinister. This, I take it, is due to the fact that there are ways we might be inconsistently epistemically influenced within 
partial relationships that then make those very relationships a particularly pernicious site or vehicle of epistemic injustice - the latter of which is considered a serious vulnerability for certain epistemic agents. Epistemic injustice, standardly understood, is the phenomenon whereby agents might be "wrongfully disadvantaged in their capacity as epistemic subjects" (Fricker, 2015) due to unfair discrimination "...in our capacity as a knower based on prejudices about the speaker." (Byskov, 2020, p. 1) The most widely discussed mechanisms of epistemic injustice are of the Frickerian variety - paradigmatically, testimonial injustice and hermeneutical injustice. The testimonial form of epistemic injustice is about a lack of credibility conferral from a would-be hearer toward a speaker because of some prejudice the hearer has about them; hermeneutical injustice is about a "structural prejudice in your conceptual framework." (Langton, 2010, p. 459)

Debates about such epistemic injustice and its operation tend to be dominated by talk about unjust interactions and targeting between social groups in friction, even if the injustices are themselves individually perpetuated. For instance, Fricker claims that the central case of testimonial injustice has to do with identity-prejudicial credibility deficit, which a speaker may suffer by "... receiving deflated credibility from the hearer owing to identity prejudice on the hearer's part, as in the case where the police don't believe someone because he is black" (Fricker, 2007, p. 5) The injustice in this standard case is, in a sense, very clear - somebody's testimony is discredited due to their being unfairly marginalized as a member of a minority group.

But recognizing and resisting this injustice as such would be even more difficult if at the same time the recipient fosters a particular stance of care towards the prejudiced agent, and if the prejudiced agent is themselves frequently blindsided by their familiarity and comfortability with their target to consider that they could be epistemically undermining them. This is precisely the troubling sort of predicament we might find ourselves in via partial relationships, yet such relationships are surprisingly under-considered in the role they play in epistemic injustice transmission. I want to clarify now that I do not view the Frickerian mechanism of epistemic injustice as spelling out a nuanced enough account of what might go wrong epistemically within partial relationships, even though epistemic injustice in general might indeed just as easily occur between close friends as with strangers or adversaries. Yet if this was all that connected partial relationships and epistemic injustice, our discussion might have ended here: we would simply have pointed out that some incidences of epistemic injustice happen to take place within partial relationships, rather than to make a point that there is some peculiar feature or set of features in partial relationships that make the epistemic injustice experienced within them unique. But, as I will argue, it is possible to form a much richer picture of how epistemic injustice is transmitted within such partial relationships by looking more closely at the peculiarities of the epistemic exchange that might occur within them.

Let us begin with an example, which hopefully illustrates why the Frickerian account of epistemic injustice is insufficient to capture the nuance generated by partial relationships. Imagine a close familial relationship, in which an older sibling consistently demeans the opinions of a younger sibling merely because the latter is taken to be 'the baby' of the family. One might argue that this is a classic case of epistemic injustice, and that partial relationships are just one of many platforms 
through which such identity prejudice-at-large might manifest. Several authors have already echoed the sentiment that children, for instance, can suffer epistemic injustice. Havi Carel and Gita Gyorffy have said that testimonial injustice can arise for children because "children may seem irrational, with reduced powers of reasoning, flawed or non-existent memories, and be easily swayed." (2014, p. 1256)

But is this all that is going on in the case of the older sibling devalidating the younger sibling's views? I am inclined to say no: it appears to me that the epistemic injustice conducted here is not merely an instantiation of a general prejudice about children assimilated into the social dynamics of a sibling relationship. Rather, there is something in particular, and peculiar, about the relationship between the older and younger sibling in question which conduces to such a phenomenon. While the part about an adult's prejudices towards younger children might be explained as a structurally commonplace issue in society, the way that epistemic injustice manifests and is experienced in the context of this relationship may only make sense by understanding the older sibling's unique brashness towards their younger sibling, and the unique anxiety and wish on part of the younger sibling to not be viewed as 'dumb' or 'stupid' by their older sibling. The missing element of this story - not captured by the Frickerian account - may be the tendency for the older sibling to insult their younger sibling in ways that would not occur to them to do with their peers, or anyone else for that matter, based on identity-prejudice; and, for the younger sibling to acclimatize to this treatment and internalize it in ways that they otherwise would not have if it were anyone else trying to undermine them.

Now consider another example. Gaslighting takes places when a hearer denies a speaker's testimony - based on the speaker's social identity - about a harm or wrong done to the speaker. (Stark, 2019, p. 221) Suppose someone gaslights their partner by denying the latter's testimony regarding being recipient to constant verbal abuse in the relationship. The person gaslighting claims that the partner is being merely dramatic and accusatory to gain attention, and even brings up the fact that the partner has struggled with mental health issues in the past to further imply that they have a propensity to create imaginary problems due to their 'emotional instability.' By gaslighting, they bring it about that “...the other person views herself as deficient or completely incompetent concerning her ability to understand, interpret situations, think, and choose for herself." (Spear, 2019, p. 7) Here again we might think that an intimate relationship constitutes the space within which a partner might try to make the other person feel inadequate and incompetent as an epistemic agent, and the way that certain gendered stereotypes about women's apparent craziness (in our case, reinforced by bringing up the partner's mental health history) might be adopted to reinforce gaslighting techniques.

Marilyn Friedman points out that partial relationships have "specific particularities which do not derive from the generic nature of the relationship nor from its formal or informal social conventions." (1991, p. 821) Thus, even emotionally abusive interactions within relationships "may be quite idiosyncratic to their interaction." (Friedman, 1991, p.821) It is therefore worth exploring the network of epistemic influences within one's partial relationships, and the particularized epistemic biases and tendencies established within them that amplify transmission of epistemic injustice. If it is at all plausible that the special ethical allowances and treatments we 
make within partial relationships extend to the epistemic realm, we ought to take seriously the fact that a generalist account of epistemic injustice may not be able to capture the more nuanced modes of transmission of epistemic injustice that occurs within more personalized relationships.

It is no trivial point that the epistemic injustices exhibited in the above examples - gaslighting within a relationship, epistemic undermining of family members, and so on - are enacted within the context of partial relationships. But why might epistemic injustice proliferate within them? One helpful text that illuminates partial ties and their epistemic corollaries is Sarah Stroud's paper on 'Epistemic Partiality in Friendship", in which she argues that friendship involves "not just affective or motivational partiality but epistemic partiality." (2006, p.499) Friendship places certain demands on our beliefs, and our belief-formation. We exercise "differential doxastic practices" (Stroud, 2006, p. 505) as constitutive of the very friendships we value. For example, if we hear unsavoury rumours or gossip concerning our friend's character, we might exert greater cognitive efforts to yield more favourable interpretations of the evidence we are given. That is, we are "less likely to conclude that our friend acted disreputably...than we would be in the case of a nonfriend." (Stroud, 2006, p. 506) Thus the friendship somehow changes not only our belief-formation processes but also the very conclusions we draw in the end about them. As I hinted at the start of this section, the literature recognizes a tension between the ethical and the epistemic when it comes to close relationships. Stroud herself claims that while a good friend really is "biased or partial", such epistemic practices "would be unfavourably evaluated by standard epistemological theories." (Stroud, 2006, p. 512) This is because these epistemic practices involve characteristics that go against what we might standardly take to be good epistemic practice, like imperviousness to new evidence and slowness to update one's beliefs. (Stroud, 2006, p. 514)

Epistemically partial practices as seen in the case of friendship seem precisely the kinds that might govern many other close ties to varying degrees - in family, platonic, and intimate relationships - and which also constitute the grounds on which the potential perniciousness of these relationships as the sites and vehicles of epistemic injustice arise. Stroud's view on epistemic partiality and friendship clues us into some of the common doxastic tendencies we exercise when it comes to our close ties which may make instances of epistemic injustice transmitted within these ties less obvious to us. We are at least sometimes inclined to perform standard doxastic practices - such as belief-updating, and so on - less well in the case of partial relationships than non-partial ones. The worry would be then that transmission of epistemically unjust treatment within partial relationships are unduly underrecognized, masked, or even tolerated because of the special epistemic allowances agents make within these relationships. This occurs on top of the fact that - as Linda Radzik says - "love is exploitable," meaning that the people we love can take advantage of the fact that we are willing to make sacrifices for them. (2005, p. 45) Agents are, in short, prone to be vulnerable or susceptible to problematic sorts of influences in partial relationships, which in the end might enable epistemic injustice to be carried out within them.

Our partiality is non-neutral as compared with our more impartial, unaffected stance. It is plausible that we are both too epistemically receptive towards our loved 
ones, and at the same time too impervious to their epistemic behaviours, as well as susceptible to be deceived or exploited by them. This might be for a number of reasons: perhaps I value what I think I know about someone more if they are someone I specially care about; perhaps I trust the word of those I care about above those I do not; perhaps I am more inclined to forgive the epistemic mishaps of my close ties as compared with strangers; perhaps there are certain things I don't want to believe about the people I am partial to; perhaps I want to impress someone I care about over and above subjecting them to certain epistemic standards; and so on and so forth. It is these partial attitudes and tendencies that make us potentially susceptible to receive epistemically unjust treatment in ways that might be overlooked as merely a special quirk of the relationship, or not taken seriously at all. That is not to say that partial relationships will necessarily lead to this phenomenon; the point is that epistemic injustice may be exacerbated by modes of partiality which involve these problematic practices of epistemic favouritism.

\subsection{Partial relationships: a pernicious site of epistemic injustice}

In the previous section, I indicated how partial epistemic modes of influence can make partial relationships prone to epistemic injustice. In this section, I will clarify why these sorts of relationships may constitute particularly pernicious sites and vehicles of epistemic injustice. The type of case I have in mind is one where agents might be made susceptible to epistemic injustice within a partial relationship. As hinted in the previous part of this paper, these are cases in which the epistemic injustice occurs in the specific context of a relationship and amongst the members that make up that relationship unit. Now there are other, more general ways that partial relationships might lead to epistemically unjust outcomes - for example, if close circles of friends make up something like an echo chamber and band together to actively discredit those outside of their network. (Nguyen, 2020, p. 142) These latter sorts of cases, however, will be left out of this paper. Furthermore, I should clarify that the epistemically partial practices which may make agents vulnerable to epistemic injustice in this context must accompany close ties. I am not making claims about, for instance, epistemic peer groups (i.e those with shared interests) (Spiekermann, 2020, p. 85) who merely epistemically concur with one another but may not otherwise be considered close relations. Rather, I refer to close relationship units that exert strong epistemic influence over one another as the very consequences of those close ties. The final clarification I want to make is that by saying partial relationships are noteworthy vehicles to epistemic injustice, I am not committing myself to the view that partial relationships are themselves necessarily unjust - I do not propose to make a final comment on the unresolved debates on partiality in ethics. I only point out that the typical nature of these relationships may, in some cases and some contexts, conduce to or amplify the incidence of epistemic injustice in worrying ways.

Let us consider, then, what makes partial relationships an especially pernicious vehicle of epistemic injustice. The kinds of special care and affective leanings we have to those with whom we share partial ties, as I've noted in the previous section, 
can extend to special epistemic allowances we make for them. These allowances can be misdirected or misplaced at the hands of one that might treat us less than epistemically just, however, and it is important that we try to dissect what goes wrong in the event that this happens. My view is that epistemic injustice may be easier to mask, harder to identify, and difficult to correct for especially within these relationships - and this makes for particularly pernicious transmissions of epistemic injustice.

The insight that partial relationships make epistemic injustices more difficult to address casts doubts over claims that have been made about ways that social oppression might confer on agents' certain epistemic advantages - even as they suffer certain disadvantages - relating to the supposed "cognitive superiority of alternative viewpoints." (Mills, 1988, p. 245) For example, the view that one who is unprivileged in their social position might have a better grasp of knowledge over social reality (Rolin, 2006, p. 125) or that those who have been oppressed have "a special kind of lucidity that functions as a corrective of the meta-blindness underlying oppression" (Medina, 2013, p. 186) is complicated if it is not only injustice or social oppression, but the further interference of close ties, that replicate the social epistemic conditions reinforced by society at large. While gaining certain insights about the world through experiences or marginalization, or being less ignorant of injustice than others, may be considered a relative epistemic advantage, we must consider also that even these epistemic gains are not neutral in context. The insights agents acquire about the world will be informed not only by their cool observations of social mechanisms, but also by the influence of their closest ties. Partiality, then, can interact with existing structures of epistemic oppression.

Take a look at the following example:

"Christina was a 12-year-old girl whose father, Michael, had been sexually abusing her for more than a year. One night, a neighbor called the police to report a violent argument between Christina's parents. When the police and Child Protective Services representative interviewed Christina, she told them what Michael had been doing to her and was removed from the home. At first, Christina's mother, Joanna, did not support or believe her daughter. Joanna was financially dependent on her husband and terrified of his violent temper.

Joanna had always told herself that it was because she was not a good enough wife, but that he was a good father and could be trusted with their daughter. It took Joanna several months to recognize that she was a victim of domestic violence, and to accept that her daughter had indeed been sexually abused. The hardest part for Joanna was to realize just how wrong she had been and to let go of her illusions about Michael. It was crucial for Joanna to receive help that would allow her to understand that the problem lay with Michael, not with her. Once she could acknowledge this, she was able to believe her daughter, and to begin healing from her own experience of abuse. Only then could Christina and Joanna restore the trust in their mother-daughter relationship."

(Account taken from report on The National Child Traumatic Stress Network's 'Coping with the Shock of Intrafamilial Sexual Abuse') 
This case is a rather horrible example of abuse that is not only obviously morally abhorrent, but also epistemically unjust. It's clear that the daughter, Christina, besides suffering from abuse because of Michael, further suffers as a result of not having her claims be believed by her own mother. It seems that the obstacles complicating this situation involves both epistemic injustice proper and the special epistemic allowances sometimes made by those embedded in partial ties. Christina ought to be believed, but Joanna finds it unimaginable to believe that someone she loves could do wrong with her own daughter; she unduly and unjustly dismisses her own daughter's testimony. Joanna may herself, of course, be in a precarious and vulnerable position (Michael may have manipulated her, subjecting her to epistemic injustice). But while we should not mistake Michael as the culprit for these multiple tragedies, we might acknowledge that Joanna is at the same time complicit in the epistemic injustice suffered by Christina, not just because she took part in epistemic injustice, but also because her complicated relationship with Michael prevented her from realizing that she wrongly disbelieved her daughter's testimony. Her lucidity about Michael, in other words, lagged in part because of her partiality to him.

Now we could put this case down as a simple instance of testimonial injustice, whereby Joanna perhaps unduly discredited her daughter's testimony on account of, partly, her own prejudices and personal suffering; yet intuitively the story seems more complicated than might be suggested by the standard Frickerian framework of something like identity-prejudicial credibility deficit. It does not seem to ring true that Joanna is merely identity-prejudiced against her daughter's testimony or even that she is naive about the possibility of abusive relationships. It is plausible to imagine that no such skepticism on Joanna's part might have surfaced in the case of another child's testimony, owing to a more impartial evaluation of testimony regarding abuse. Rather, Joanna's particular relation to Michael, and the way that her and Michael's relationship informs her inclination to believe - or disbelieve - her daughter, appears to play a major role in why Christina suffered in this example.

Of course, we can also apply other frameworks to explain Joanna's falling short of lucidity in the circumstances. From a standpoint epistemological viewpoint, often discussed by feminist philosophers, we might say that "an agent's social identity [makes] a difference to what an epistemic agent is in a position to know" (Toole, 2019, p. 598) Scholars recognize that "experiences, social practices, social values and the ways in which perception and knowledge production are socially organized" mediate the social situatedness of knowledge. (Stoetzler and Yuval-Davis, 2002, p. 316) Perhaps the psychological precarity of Joanna's subjugated position - as a potentially gaslighted woman in midst of an abusive and manipulative relationship - serves as a barrier to the truth she might otherwise have come to know. On this sort of view, we might want to argue that Joanna's embeddedness in Michael's dominating narrative is to blame for what is perhaps her inadvertent involvement in epistemic injustice towards Christina. This line of thinking is entirely compatible with my overarching thesis, which is that partial relationships can amplify and exacerbate epistemic injustice.

But my account further reiterates that the wrong of this case is not simply reducible to inevitable instantiations of testimonial injustice, even if at surface level it appears like a basic case of testimonial injustice. My analysis allows us to observe 
that there is something especially terrible and frightful about it being the case that it was Christina's own mother who failed to believe Christina's testimony - terrible precisely because the mode of epistemic injustice transmission was not impersonal, but had everything to do with who Michael is to Joanna and what Joanna is inclined to believe on the basis of that. Indeed, thinking about partial ties in tandem with agents' individuated social positions, and the social structures in which they are embedded, can reveal just how much the personal can overlay the structural, further complicating agents' standing in their social environment. The key here is to recognize that it is not merely the impersonal social positionings which one occupies that raises or lowers one's vulnerability to epistemic injustice; it is also partly determined by the peculiarities of individual personal ties, which can play a major role in one's susceptibility to epistemic injustice.

What this case shows us, I think, is that stories of epistemic injustice occurring within close relationships present unique challenges. Epistemic injustice is easier to mask, obscure, or overlook within these relationships if agents suffering from it, or even those perpetuating it, appeal to some justification or excuse apparently warranted by some special relationship - excuses which are otherwise unavailable in more impartial relationships. ${ }^{1}$ Moreover, it is also plausible that these relationships tend not to be given much attention as sites of epistemic injustice in the first place, given that a large portion of the literature focuses on relations that are often structural or impersonal ones. The lack of attention on the phenomenon of epistemic injustice within partial relations helps explain why instances of epistemic injustice can go undetected; but, as we've seen above, the nature of personal ties can present just as much of a problem as the issues generated by the more general social dynamics.

Epistemic injustice is also more difficult to identify - both internally and from a more outside perspective - when instances occur within partial relationships. We saw that Joanna, for instance, struggled at length with the high-stakes implications generated by Christina's testimony - namely that someone she loves (or thought she loved) is capable of doing such terrible things, especially to her own daughter. Unlike, say, a neighbour or anyone else who is not privy to these high stakes in their assessment of a plausible testimony, Joanna failed initially to identify her errors when evaluating the circumstances. It also does not help matters that the epistemic exchanges within partial relationships are not typically taken to fall under the realm of public scrutiny. As Pauline Kleingeld and Joel Anderson point out, ethical issues that arise within something like family relationships are difficult to adjudicate, largely because family and justice are "understood as belonging to different spheres, one private and the other public." (2014, p. 3) Justice in the public sphere is supposed to serve as an impersonal, principled way to adjudicate conflicts, whereas the interactions in the domestic realm of the loving family are governed by affection and

\footnotetext{
1 We might easily imagine agents defending what might plausibly be taken as an instance of epistemic injustice by way of protests like "I know him, and he would never do something like that" or "I don't believe my friend would say that." Similarly, one who is perpetuating or complicit in some form of epistemic injustice might defend themselves by appealing to the same kinds of excuses.
} 
concern for "...the needs of particular loved ones." (Kleingeld and Anderson, 2014, p. 3) Issues within partial relationships, then, are often left to be dealt with exclusively for those actually involved in them. And until someone attempts to intervene from the outside (as did the neighbour in the example given above), the problems that surface in these partial ties - including the ones due to epistemic biases that enable or prolong the presence of epistemic injustice - may go unresolved. Moreover, if agents are too adamant and defensive to heed outside perspectives, perhaps even outside intervention is insufficient to address such problems.

This makes epistemic injustice correspondingly especially difficult to mitigate, regulate, and correct in partial relationships. How exactly would we target epistemic injustice in sensitized and seemingly private spaces like partial relationships? Although various general proposals for the mitigation of epistemic injustice might apply in this context, the tendencies and features of specific partial relationships are themselves peculiar to those relationships, so it is unclear how general mitigation procedures might play out within them. Consider, for instance, Miranda Fricker's suggestion of developing the virtue of testimonial justice, which involves critical self-awareness and self-monitoring habits. But is "a corrective anti-prejudicial virtue that is distinctively reflexive in structure" (Fricker, 2007, p. 91) adequate to capture and ameliorate the example we've just studied? We might suppose that Joanna, for instance, is not necessarily lacking in the ability to make reasonable assessments of children's testimony - it is her involvement with an abuser, whom she is manipulated by and fails to be sufficiently emotionally detached from, that interferes with her ability to believe her own daughter. What needs fixing, then, does not seem to be a general skill or lack of virtue, if we can grant that Joanna is not particularly stunted in her critical reflexive abilities of agents' testimonies outside of these special partial bonds.

Now consider another example of a mitigating strategy for epistemic injustice, which Havi Carel and Ian Kidd have suggested for the more specific context of illness and healthcare practice. They claim that "structures of contemporary healthcare practice encourage epistemic injustice because they privilege certain styles of articulating testimonies...e.g. privileging impersonal third-person reports, in ways that structurally disable certain testimonial and hermeneutical activities." (Carel and Kidd, 2014, p. 4) They suggest a phenomenological toolkit as a way to remedy some of this epistemic injustice. The toolkit is meant to be one that helps patients develop an understanding of their illness in several steps that include "the phenomenological reduction, thematizing illness, and reviewing the ill person's being in the world." (Carel and Kidd, 2014, p. 23) The crucial aspect to note in this kind of proposal is that it presumes relationships which are meant to be impartial and consistent, like that of a doctor-patient relationship. The toolkit, then, can target a wide range of cases that occur within the healthcare context. But is it possible to develop a "toolkit" for those in partial, and non-professional, relationships?

Given that the spectrum of our affective leanings towards particular others vary, and are unique to those partial relationships, it is unclear whether trying to exercise certain epistemic virtues in general, or making use of epistemic toolkits, can fully target and ameliorate the kinds of epistemic vulnerabilities discussed in this section. It doesn't seem quite appropriate, either, to advise that individuals counter their 
epistemically preferential or favourable tendencies toward their special others by treating them, instead, with greater epistemic suspicion. And, given that I've clarified earlier in this section that I do not flat out condemn partial relationships per se as unjust, it goes without saying that encouraging people to foster fewer close ties in the first place, or to avoid entering into partial relationships in general, would also be a wrong-headed suggestion, given the tendency in ethics to try and reconcile value with partiality. It is rather unfortunate, then, that the complex and deeply influencing ties that constitute partial relations make resolving epistemic injustice transmission within them all the more challenging.

Recognizing and dealing with epistemic injustice as they occur within partial relationships does not seem to leave us with easy solutions that can be generalized, given the unique instantiations and circumstances of people's partial relationships. Be that as it may, hopefully this section illuminated the fact that it is in the first place possible for partial relationships to be a site of epistemic injustice in ways that are unaccounted for by - and are not reducible to - the paradigmatic mechanisms of epistemic justice transmission.

\section{Conclusion}

I have claimed that partial relationships are prone to transmit epistemic injustice in particularly pernicious ways, due to the epistemically preferential features that typify such partial relationships. Partial relationships are not only negatively implicated as a proxy for epistemic injustice; the way epistemic injustice is experienced and dealt with may itself be irreducibly informed by the context of specific partial relationships. It should worry us that, quite besides the impersonal structures and systems of injustice that make up many paradigmatic cases of epistemic injustice, close and intimate relationships are not immune to epistemic injustice transmission. On the contrary, they may exacerbate instances of epistemic injustice by making it easier to mask, harder to detect, and more difficult to correct.

Funding Funding was provided by Velux Fonden. The project number is: 00026589

\section{References}

Brighouse, Harry and Swift, Adam. (2009) 'Legitimate Parental Partiality,' Philosophy \& Public Affairs, 37 (1), p43-80.

Byskov, M. F. (2020) 'What Makes Epistemic Injustice an "Injustice”?', Journal of Social Philosophy (early view). Available at: https://doi.org/10.1111/josp.12348. Accessed 1 November 2020.

Carel, Havi. and Gyorffy, Gita. (2014) 'Seen but not heard: children and epistemic injustice', The Lancet, 384, p1256-1257.

Carel, H. H. and Kidd, I. J. (2014) 'Epistemic injustice in healthcare: a philosophical analysis,' Medicine, Health Care and Philosophy, 17(4), p529-540.

Crisp, Roger. (2018) Against Partiality. http://hdl.handle.net/1808/26747. Accessed 1 November 2020.

Douglas, Thomas. (2015) 'Parental partiality and the intergenerational transmission of advantage', Philosophical Studies, 172, p2735-2756. 
Feltham, Brian. (2010) Introduction: Partiality and impartiality in ethics. In Partiality and Impartiality: Morality, Special Relationships, and the Wider World, eds. Brian Felthman and John Cottingham, 1-25. Oxford: Oxford University Press.

Fricker, Miranda. Epistemic Injustice. In Oxford Bibliographies in Philosophy. Available at: https://www. oxfordbibliographies.com/view/document/obo-9780195396577/obo-9780195396577-0274.xml. Accessed 7 November 2020.

Fricker, Miranda. (2007) Epistemic Injustice: Power and the ethics of knowing. Oxford: Oxford University Press.

Friedman, Marilyn. (1991) 'The practice of partiality,' Ethics, 101, p818-835.

Goldman, Alvin. (2009) 'Social Epistemology: Theory and Applications', Royal Institute of Philosophy Supplement, 64, p1-18. https://doi.org/10.1017/S1358246109000022

Hooker, Brad. (2013) Egoism, partiality, and impartiality. In The Oxford Handbook of the History of Ethics, ed. Roger Crisp, 710-728. Oxford: Oxford University Press.

Keller, Simon. (2013) Partiality. Princeton: Princeton University Press.

Kleingeld, Pauline. and Anderson, Joel. (2014) 'Justice as a family value: How a commitment to fairness is compatible with love', Hypatia, 29, 320-336.

Kolodny, Niko. (2010) Which Relationships Justify Partiality? General Considerations and Problem Cases. In Partiality and Impartiality: Morality, Special Relationships, and the Wider World, eds. Brian Felthman and John Cottingham, 169-193. Oxford: Oxford University Press.

Langton, Rae. (2010) Review, Hypatia, 25(2), p459-64.

Medina, José. 2013. The Epistemology of Resistance: Gender and Racial Oppression, Epistemic Injustice, and The Social Imagination. Oxford: Oxford University Press.

Miller, David. (2005) 'Reasonable Partiality Towards Compatriots', Ethical Theory and Moral Practice, 8, p63-81.

Mills, Charles W. (1988) 'Alternative Epistemologies', Social Theory and Practice, 14(3), p.237-263.

Nguyen, C. Thi. (2020) 'Echo Chambers and Epistemic Bubbles', Episteme, 17(2), p141-161.

Paul, Sarah, and Morton, Jennifer. (2018) 'Believing in Others', Philosophical Topics, 46(1), p75-95.

Quinton, Anthony. (2004) 'Two kinds of social epistemology', Episteme, 1(1), p7-9.

Radzik, Linda. (2005) 'Justice in the family: A defence of feminist contractarianism', Journal of Applied Philosophy, 22(1), p45-54.

Rolin, Kristina. (2006) 'The Bias Paradox in Feminist Standpoint Epistemology', Episteme, 3(1), p125-136.

Scheffler, Samuel. (2010) Morality and Reasonable Partiality. In Partiality and Impartiality: Morality, Special Relationships, and the Wider World, eds. Brian Felthman and John Cottingham, 98-130. Oxford: Oxford University Press.

Spear, Andrew D. (2019) 'Epistemic dimensions of gaslighting: peer-disagreement, self-trust, and epistemic injustice,' Inquiry, DOI: https://doi.org/10.1080/0020174X.2019.1610051.

Spiekermann, Kai. (2020) 'Epistemic Network Injustice', Politics, Philosophy, and Economics, 19(1), p83-101.

Stark, Cynthia A. (2019) 'Gaslighting, Misogyny, and Psychological Oppression', The Monist, 102, p221-235.

Stoetzler, Marcel, Yuval-Davis, Nira. (2002) 'Standpoint theory, situated knowledge and the situated imagination', Feminist Theory, 3(3), p315-333.

Stroud, Sarah. (2006) 'Epistemic partiality in friendship,' Ethics, 116, p498-524.

Stroud, Sarah. (2010) 'Permissible Partiality, Projects, and Plural Agency' In Partiality and Impartiality: Morality, Special Relationships, and the Wider World, eds. Brian Felthman and John Cottingham, 131-149. Oxford: Oxford University Press.

Sullivan, Emily, Sondag, Max, Rutter, Ignaz, Meulemans, Wouter, Cunningham, Scott, Speckmann, Bettina and Alfano, Mark. (2020) 'Vulnerability in Social Epistemic Networks', International Journal of Philosophical Studies, 28(5), p731-753.

Toole, Briana. (2019) 'From Standpoint Epistemology to Epistemic Oppression', Hypatia, 34(4), p598-618.

Tronto, Joan C. (2012) 'Partiality Based on Relational Responsibilities: Another Approach to Global Ethics', Ethics and Social Welfare 6(3), p303-316.

Wolf, Susan. (1992) 'Morality and Partiality', Philosophical Perspectives, 6, p243-259. 
Publisher's Note Springer Nature remains neutral with regard to jurisdictional claims in published maps and institutional affiliations. 